\title{
Leiomyoma of the Female Urethra-A Rare Tumor: Case Report and Review of the Literature
}

\author{
Mrinal Pahwa, Yusuf Saifee, Archna R. Pahwa, and Manu Gupta \\ Department of Urology, Sir Ganga Ram Hospital, New Delhi 110060, India \\ Correspondence should be addressed to Mrinal Pahwa,drmrinalpahwa@gmail.com
}

Received 8 March 2012; Accepted 6 June 2012

Academic Editors: J. P. Gearhart and N. Tanji

Copyright () 2012 Mrinal Pahwa et al. This is an open access article distributed under the Creative Commons Attribution License, which permits unrestricted use, distribution, and reproduction in any medium, provided the original work is properly cited.

Leiomyoma is a benign smooth muscle tumor which is rarely found in urethra. Only a handful of cases have been reported in the literature. We hereby report a case of urethral leiomyoma in a twenty-seven-year-old female who presented with intermittent hematuria. Mass was completely excised with a rim of normal tissue. Patient remained asymptomatic with no evidence of recurrence in followup.

\section{Introduction}

Urethral leiomyomas are rare benign tumors arising from the smooth muscle of urethra. These are more common in women [1]. Approximately 40 odd cases have been reported in world literature [1-9].

\section{Case Report}

A twenty-seven-year-old woman presented with intermittent hematuria and a mass coming out from the vagina. On examination, she was found to have a fleshy mass at the urethral meatus (Figure 1). She did not have any voiding symptoms or perineal pain. On urethroscopy, the mass was occupying the mid and distal urethra from 10 o' clock to 6 o' clock position. Cystoscopy was normal. The urethra could be calibrated up to 18 Fr. The mass was excised and the proximal urethral mucosa was mobilized and approximated with the distal edge. After excision of the tumor, the urethra could admit a 30 Fr dilator. Patient was catheterized for 48 hours and voided well on catheter removal. Histopathological examination revealed an encapsulated tumor composed of spindle-shaped smooth muscle fibers arranged in a whorling pattern. On immunohistochemical examination tumor was positive for vimentin and smooth muscle actin. A diagnosis of leiomyoma was made (Figure 2).

\section{Discussion}

Leiomyoma of urethra is a rare condition affecting women more than men. The tumor is most common in third and fourth decade; the mean age of the appearance is around 41 years $[8,9]$. Distal urethra can be affected but proximal segment is the most common site [3]. Common presenting symptoms include urinary tract infection (64.3\%), a mass (50\%), dyspareunia, urinary retention, and irritative lower urinary tract symptoms. The tumor has been reported to enlarge during pregnancy and shrink after delivery, suggesting a possible hormonal dependence [5].

A differential diagnosis of urethrocele, a urethral diverticulum, caruncle, and malignancy should be considered. A careful clinical examination, urethroscopy, and radiological examination of the lower urinary tract are essential to distinguish it from urethrocele, urethral diverticulum, and caruncle. However, a microscopic examination is indispensable to exclude possibility of a malignancy although lately transvaginal ultrasound and MRI have been used to indicate the benign nature of the disease [10].

Urethral leiomyomas must also be differentiated from paraurethral leiomyomas, which may be removed without disrupting the urethral muscle or mucosa. No malignant transformation or recurrence has been reported. Local 


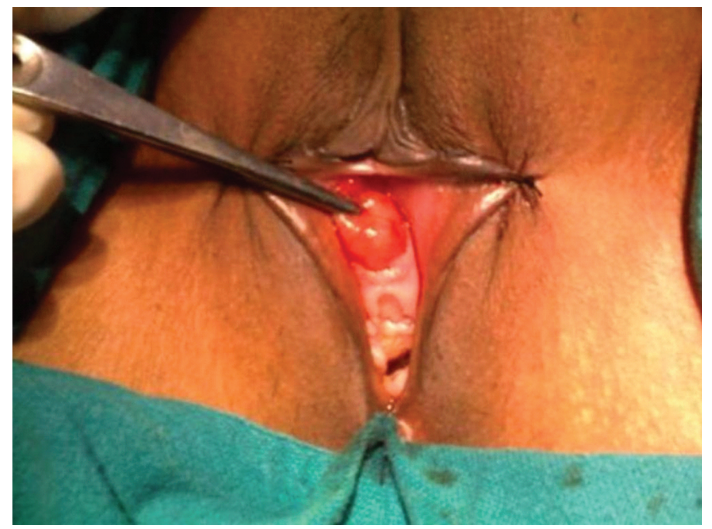

Figure 1: Local examination revealed a $2 \times 2 \mathrm{~cm}$ growth arising from urethral meatus.

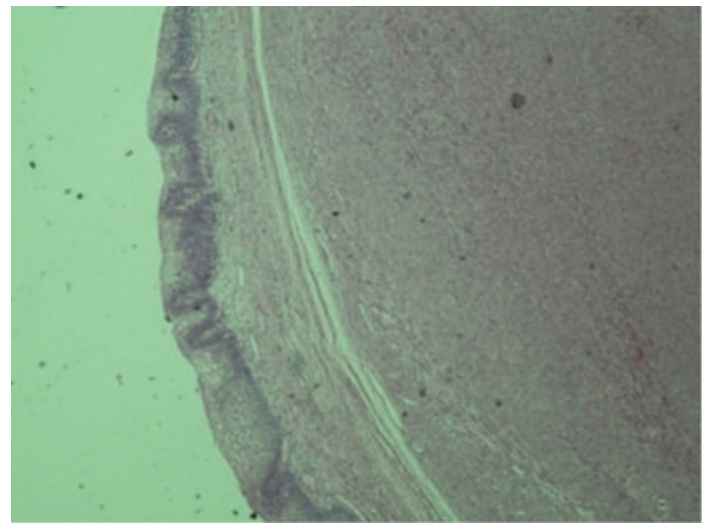

FIgURE 2: Histopathology 40x-bladder mucosa with submucosal encapsulated leiomyoma.

surgical excision is the treatment of choice for urethral leiomyoma [6].

Our case was different as the patient presented with episodic hematuria unlike the previously reported cases. The mass was located in distal urethra which is not the common site of presentation of leiomyoma in females.

\section{Conflict of Interests}

Written consent was taken from the patient for publication of the paper. The authors also disclose that there is no conflict of interests.

\section{References}

[1] D. E. Shield and R. M. Weiss, "Leiomyoma of the female urethra," Journal of Urology, vol. 109, no. 3, pp. 430-431, 1973.

[2] G. Diószeghy and A. Kiss, "Leiomyoma of the female urethra," International Urology and Nephrology, vol. 30, no. 5, pp. 603607, 1998.

[3] M. C. Lee, S. D. Lee, H. T. Kuo, and T. W. Huang, "Obstructive leiomyoma of the female urethra: report of a case," Journal of Urology, vol. 153, no. 2, pp. 420-421, 1995.

[4] L. Noto, "Obstructive urethral leiomyoma in a female," British Journal of Urology, vol. 55, no. 2, article 239, 1983.
[5] M. Fry, J. S. Wheeler, J. A. Mata Jr., D. J. Culkin, E. St Martin, and D. D. Venable, "Leiomyoma of the female urethra," Journal of Urology, vol. 140, no. 3, pp. 613-614, 1988.

[6] P. M. Deka and T. P. Rajeev, "Leiomyoma of the female urethra: a case report," Urologia Internationalis, vol. 71, no. 2, pp. 224225, 2003.

[7] H. B. Goldman, S. E. McAchran, and G. T. MacLennan, "Leiomyoma of the urethra and bladder," Journal of Urology, vol. 177, no. 5, article 1890, 2007.

[8] K. M. Chong, J. Chuang, Y. L. Tsai, and J. L. Hwang, "A rapidly growing paraurethral myoma with profuse bleeding from a mucosal vessel: report of a case," Gynecologic and Obstetric Investigation, vol. 61, no. 2, pp. 87-89, 2006.

[9] B. Özel and C. Ballard, "Urethral and paraurethral leiomyomas in the female patient," International Urogynecology Journal and Pelvic Floor Dysfunction, vol. 17, no. 1, pp. 93-95, 2006.

[10] P. Pavlica, A. Bartolone, C. Gaudiano, and L. Barozzi, "Female paraurethral leiomyoma: ultrasonographic and magnetic resonance imaging findings," Acta Radiologica, vol. 45, no. 7, pp. 796-798, 2004. 


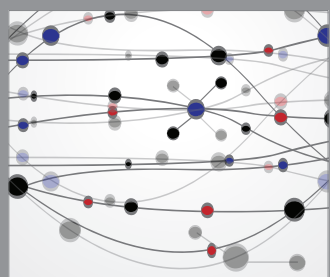

The Scientific World Journal
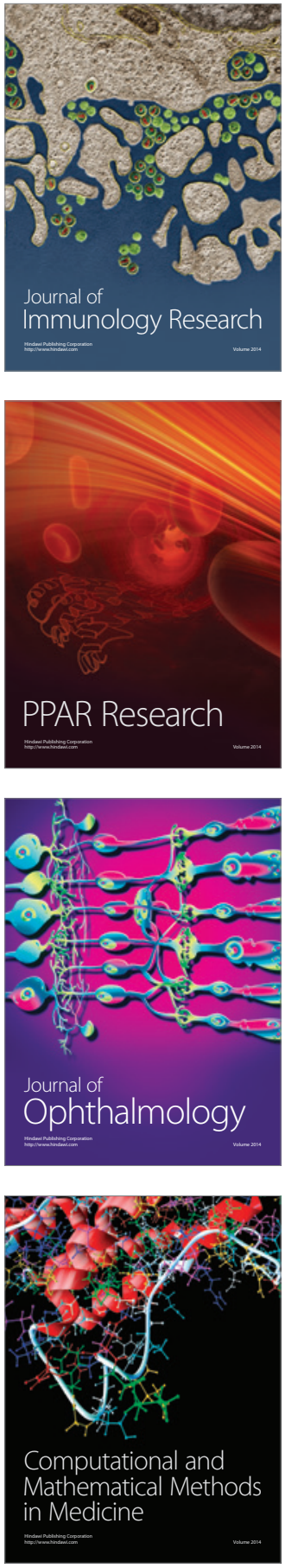

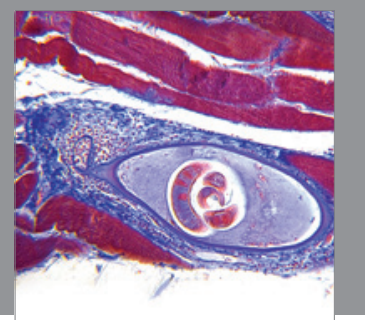

Gastroenterology

Research and Practice
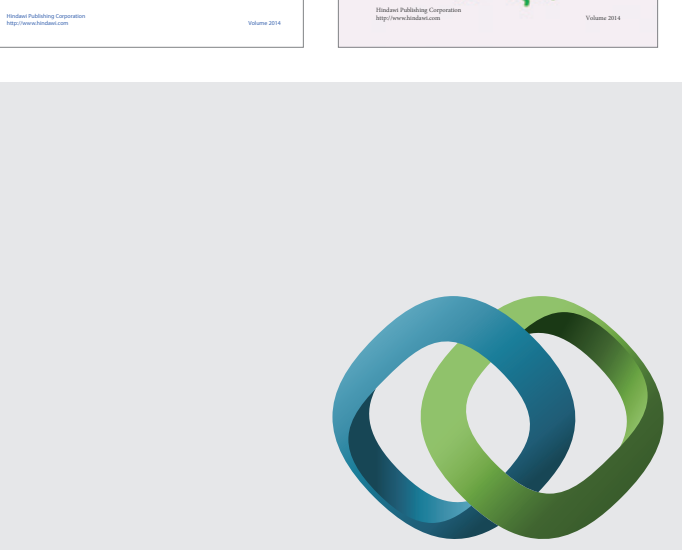

\section{Hindawi}

Submit your manuscripts at

http://www.hindawi.com
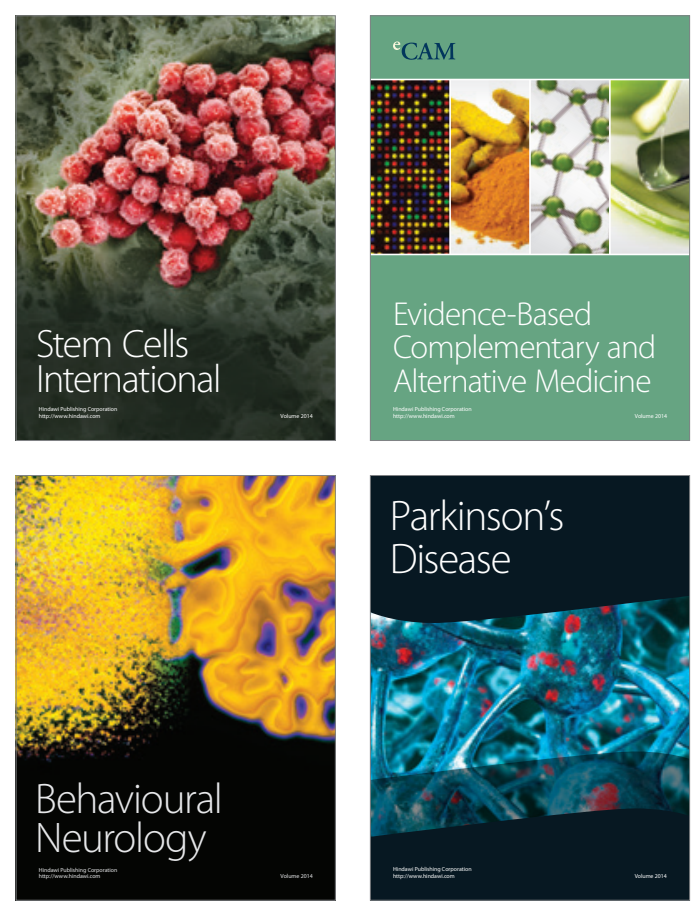

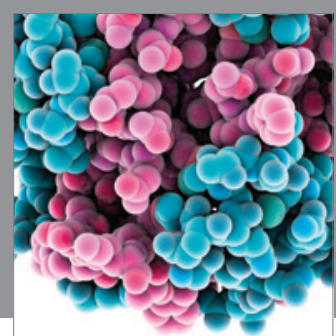

Journal of
Diabetes Research

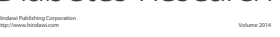

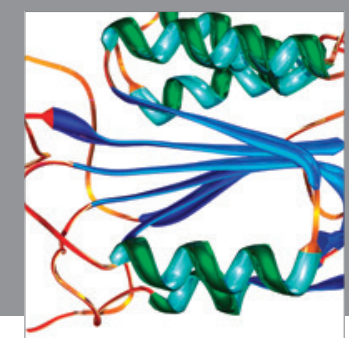

Disease Markers
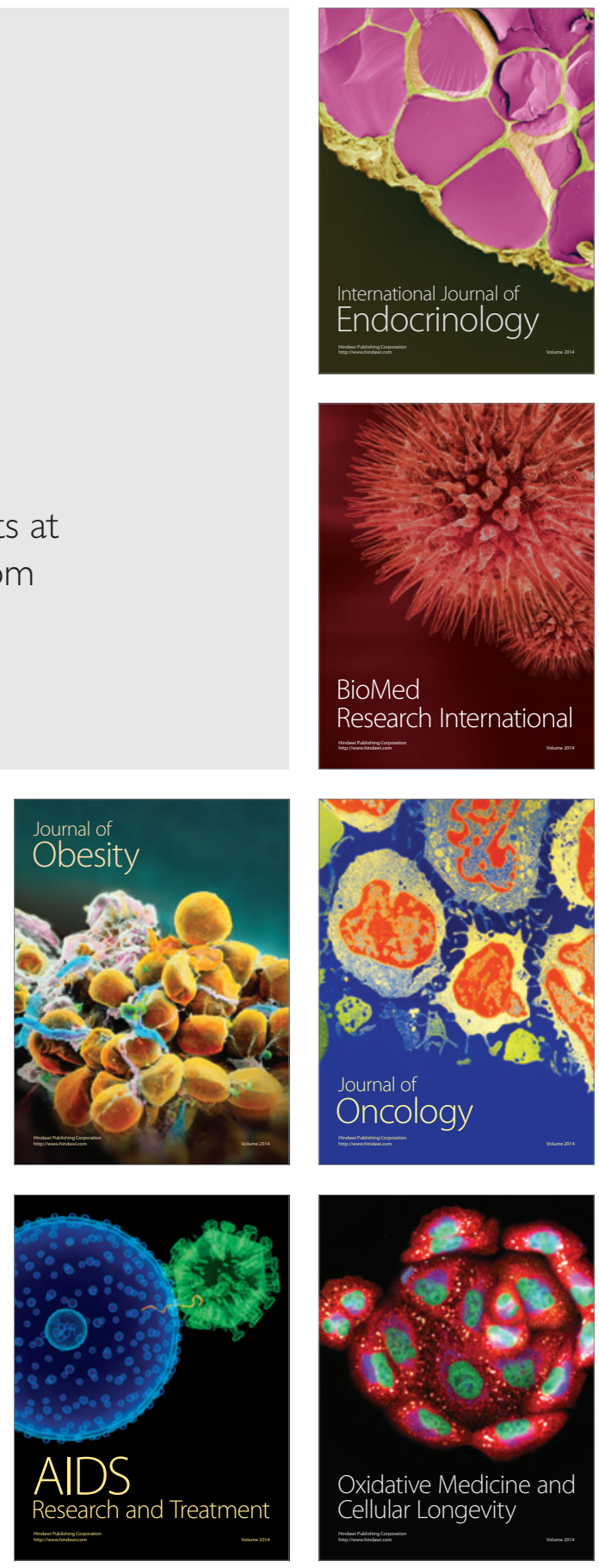